\title{
UMA ANÁLISE DAS AVALIAÇÕES EM LARGA ESCALA SOB A PERSPECTIVA DE PAULO FREIRE
}

Fabio Perboni, Cristiano Amaral G. Di Giorgi

Doutorando FCT/UNESP. PPGE - FCT/UNESP. E-mail: fabioperboni@terra.com.br

\section{RESUMO}

No presente trabalho propomos uma reflexão sobre as políticas de avaliação em larga escola da educação básica, por entendermos tratar-se de uma questão central para a compreensão das políticas públicas, uma vez que se constituem num dos elementos de controle da gestão escolar, do currículo e em última análise do próprio trabalho do professor. Resultado de uma abordagem qualitativa, de cunho bibliográfico o texto está dividido em duas partes, na primeira parte, debatemos o contexto de produção das reformas educacionais de viés neoliberal, por entendermos que essa conjuntura gestou as políticas de avaliação da atualidade. Em seguida, pontuaremos alguns aspectos relevantes da avaliação educacional em larga escala e as contribuições de Paulo Freire para este debate. Ao final concluímos que o modelo de avaliação em larga escala assenta-se em uma concepção de educação que podemos chamar de neoliberal, afastando-se do modelo de educação transformadora e democrática previsto na legislação.

Palavras-chave: Avaliação Educacional; Pensamento de Paulo Freire; Políticas Públicas; Avaliação em Larga Escala.

\section{INTRODUÇÃO E OBJETIVOS}

A avaliação em larga escala da educação básica constitui-se na atualidade num dos temas que perpassam a política pública educacional. Diante da amplitude da temática e, conscientes da impossibilidade de responder a todas inquietações procuramos organizar o presente texto pensando na avaliação "da" Educação Básica - em uma perspectiva da política educacional - e não a avaliação "na" Educação Básica - em uma perspectiva pedagógica -, embora saibamos que essas duas dimensões estão dialeticamente ligadas.

Dividimos o texto em duas partes, na primeira, debateremos o contexto de produção das reformas educacionais de viés neoliberal, por entendermos que essa conjuntura gestou as políticas de avaliação em larga escala da atualidade. Nesse sentido, é importante compreender o contexto das reformas educacionais para compreendermos os sentidos atribuídos à avaliação em larga escala na atualidade. Para tanto, nos debruçaremos particularmente nas duas últimas décadas. Em seguida, pontuaremos alguns aspectos relevantes da avaliação educacional em larga escala. Ao final apresentamos algumas considerações sobre a temática, tentando relacionar cada uma das partes. 


\section{METODOLOGIA}

O presente trabalho centra-se, particularmente, na discussão da política de avaliação em larga escala, para tanto, valeu-se de levantamento e análise bibliográfica e documental. $\mathrm{Na}$ tentativa de trazermos novas contribuições acerca da temática, recorremos a Freire (2001a) e Freire e Shor (1986) que ao lado de especialistas em avaliação em larga escala (SOUZA; OLIVEIRA, 2003; WERLE, 2011; BONAMINO, SOUSA, 2012; MARTINS, SOUSA, 2012) constituem-se no referencial teórico adotado na construção deste ensaio.

\section{DISCUSSÃO}

\section{Reformas Educacionais}

A prática de medir o desempenho educacional não é nova e está presente no Brasil desde a década de 1930, embora com outros formatos. A adoção de enfoques psicológicos usados nos Estados Unidos previa possibilidades de medir as habilidades e aptidões, com testes para medir o quociente de inteligência e fazer também medições da aprendizagem.

Contudo, foi na década de 1980 que as avaliações passaram a se desenvolver sob a perspectiva que temos na atualidade, voltadas para medições em larga escala, com objetivos que vão além do diagnóstico de aprendizagens, se inserindo em um arcabouço mais amplo de controle e transformação da política educacional.

As reformas educacionais que marcaram as últimas décadas comportam algumas características marcantes. Em uma perspectiva histórica, Beisiegel (2005) destaca que as transformações na educação foram marcadas por uma contínua democratização do acesso, processo que se insere num contexto mais amplo das transformações sociais. Esta expansão da rede de ensino foi acompanhada por uma crescente crise educacional causada por um insuficiente investimento financeiro, com a improvisação de prédios e mesmo de professores.

Os contornos da percepção de crise no sistema educacional estão inseridos na própria dinâmica de transformação social, política e econômica da sociedade e ao modelo educacional que acompanhou este processo.

Com as mudanças que afetaram a educação e a sociedade ao longo do século XX a escola passou a sofrer críticas em relação à qualidade. Para Beisiegel (2005), estas críticas podem ser classificadas em dois padrões, de certa forma, opostos. De um lado, uma crítica conservadora, destaca a perda dos padrões de qualidade do passado e defende a volta de elementos existentes 
no passado tais como o exame de admissão e os mecanismos de seleção da escola, destacando sua função social de encaminhar o jovem para a escola superior.

Por outro lado, setores progressistas avançam na crítica ao processo de democratização das oportunidades. Esta perspectiva centra-se na questão ideológica do sistema escolar, que se ampliou atingindo todos os seguimentos da sociedade.

Nesse contexto, na virada do século XX para o século XXI, identifica-se um processo de "invasão" de novos termos no discurso político e econômico. Chesnais (1996, p. 24), ao analisar aspectos gerais da globalização, afirmar que estes "novos termos" estão permeados de conotações e, ao mesmo tempo, são vagos, pois “[...] cada qual pode empregá-los exatamente no sentido que lhe for conveniente, dar-lhes o conteúdo ideológico que quiser".

Compreendendo que a educação se insere em um processo mais amplo de transformação da sociedade, percebemos no uso de termos como "descentralização", "gestão democrática", "autonomia", "qualidade do ensino" e "avaliação" o mesmo fenômeno que se apresenta de forma até mais acentuada, uma vez que carregados de polissemia, são essenciais para direcionamento das políticas públicas na área.

\section{Avaliação da Educação Básica}

Considerando o contexto de reformas educacionais subscrito podemos situar a avaliação em larga escala como uma das características mais marcantes desse momento.

As políticas de avaliação inserem-se em uma lógica mais ampla de transformação do papel do Estado, em geral, com reflexos importantes na área específica da política educacional.

Peroni e Adrião (2005) apontam para um movimento, à primeira vista paradoxal, de descentralização da atuação do Estado, concomitantemente com a centralização de outras ações. Assim, ao mesmo tempo em que centralizaram as ações sobre a avaliação e o currículo, por exemplo, se descentralizam as ações de execução das políticas para o âmbito local ou das escolas, ou seja, criam-se mecanismos de controle para influenciar e determinar questões gerais e estruturantes, delegando à escola a autonomia para executá-las.

No campo teórico o que se debate são quais as consequências dessas práticas no cotidiano das escolas. Nessa linha argumentativa, Martins e Souza (2012) exploraram a produção acadêmica sobre a avaliação em larga escala e a gestão, agrupando os trabalhos produzidos de entre os anos 2000 e 2008 em quatro eixos: efeitos escola ou características das escolas eficazes; resultados das avaliações e perfis de diretores e modelos de gestão; avaliação institucional e, por último, uso dos 
resultados das avaliações na formulação de ações e políticas públicas educacionais e processos de gestão.

A variedade de temáticas e a crescente quantidade de estudos que abrangem as diferentes perspectivas da avaliação da Educação Básica sinalizam a premência dessa problemática no contexto educacional, indicando ainda a centralidade que a mesma assumiu na política pública educacional brasileira.

As avaliações externas com certeza desempenham função central nesse processo. Werle (2011) aponta para a existência de um histórico de implementação das avaliações em larga escala no Brasil, destacando sua crescente interferência na operacionalização do ensino.

Com base em estudos internacionais, Bonamino e Souza (2012) corroboram esse entendimento, destacando que essas políticas de avaliação da Educação Básica podem ser classificadas em três gerações, que se diferenciam pelas interferências que provocam nas escolas.

Uma primeira geração pode ser caracterizada pelo objetivo de acompanhar a qualidade da educação, mas os resultados das avaliações não são usados ou retornados para a escola, servindo mais para o diagnóstico do sistema. A segunda e terceira gerações têm como aspecto principal a responsabilização dos agentes escolares pelos resultados das avaliações, respectivamente de forma "branda" ou "forte".

$\mathrm{Na}$ denominada responsabilização branda, presente na chamada segunda geração, as implicações em torno dos resultados são mais simbólicas, como a devolução dos resultados para as escolas, professores e sociedade. Caracterizadas pelo chamado rankeamento de escolas, estimulam a competição entre as unidades e o engajamento de seus integrantes na busca de sua melhoria.

Nas avaliações de terceira geração, marcadas pela responsabilização forte, os resultados envolvem políticas de sanções e/ou de recompensas em função dos resultados alcançados. No Brasil têm sido crescentes as proposições em torno de políticas de bonificação, sistema já implementado em alguns sistemas estaduais e municipais, enquanto ainda não é comum punições às escolas ou a seus profissionais com base nos resultados.

Nesse sentido, outros fatores contribuem e/ou deveriam ser considerados como indicadores de qualidade do ensino acabam por ser desprestigiados ou ignorados na definição das políticas educacionais. 


\section{RESULTADOS}

0 que pensa Freire sobre a avaliação?

Um primeiro elemento a se considerar nessa análise é que Freire não analisa a avaliação de forma dissociada de outros aspectos da prática educacional, como por exemplo, a formação permanente dos professores.

Em sua obra a ênfase está no uso que deve ser dado à qualquer avaliação, afirmando que esta não deve ser usada para expor ou mesmo para punir os docentes. Na visão do autor,

[...] Pensar a prática enquanto a melhor maneira de aperfeiçoar a prática. Pensar a prática através de que se vai reconhecendo a teoria nela embutida. A avaliação da prática como caminho de formação teórica e não como instrumento de mera recriminação da professora (FREIRE, 2001, p.11, grifos nossos).

A tradição autoritária que acompanha a escola pública em praticamente toda a história da educação brasileira propiciou a criação de uma cultura de rejeição frente aos momentos/instrumentos de avaliação, tradicionalmente utilizados como mecanismos de punição e de controle. Entretanto, na ótica freireana a avaliação é considerada como parte do processo de aprendizagem tanto dos alunos como dos professores.

A segunda razão por que a avaliação se impõe está exatamente na necessidade que têm os seus sujeitos de, acompanhando passo a passo a ação dando-se, observar se seus objetivos estão por ser alcançados. Afinal, verificar se a prática está levando à concretização do sonho por causa do qual estamos praticando. Neste sentido, a avaliação da prática é fator importante e indispensável à formação da educadora. Quase sempre, lamentavelmente, avaliamos a pessoa da professora e não sua prática. Avaliamos para punir e não para melhorar a ação dos sujeitos e não para formar (FREIRE, 2001, p.11, grifos nossos).

No mesmo sentido, ao tratar do modelo punitivo de avaliação, destaca que embora pouco implantada no Brasil, a análise do contexto em que se desenvolve a prática é importante para um avanço da educação de qualidade. A avaliação é entendida como parte do processo de aprendizagem e não um elemento separado da prática, ou mesmo separado da reflexão sobre a prática, neste sentido a avaliação, a reflexão e a prática são elementos indissociáveis.

[...] outro equívoco que cometemos por causa, possivelmente, desse deslocamento de foco - em lugar de avaliar para melhor formar, avaliamos para punir - está em que em pouco ou quase nada nos preocupa o contexto em que a prática se dará de uma certa maneira com vistas aos objetivos que temos (FREIRE, 2001, p.11-12, grifos nossos). 
Assim, torna-se necessário ressignificar as práticas e processos de avaliação. Para tanto, apoiados em Freire, defendemos que a avaliação seja construída no interior das escolas, pelos sujeitos envolvidos no processo educativo e, que esta tenha tão somente como objetivo, "reprogramar" a própria prática.

Com um posicionamento radicalmente contrário ao que se convencionou estabelecer como política pública de avaliação dos resultados, o autor destaca que "programar e avaliar não são, contudo, momentos separados um à espera do outro. São momentos em permanentes relações. A programação inicial de uma prática, às vezes, é refeita à luz das primeiras avaliações que a prática sofre" (FREIRE, 2001, p.11).

Em uma crítica direta ao modelo de avaliação que vem sendo implementado na atualidade Freire e Shor (1986, p.51), já sinalizavam na década de 1980, como uma necessidade dos administradores em criar dados quantificáveis, sufocando uma pedagogia transformadora em favor de práticas de controle e importação de modelos de administração empresarial para a educação.

Os interesses do capital predominam na sociedade e controlam a eleição de servidores públicos, através dos meios de comunicação de massa, dos grupos de pressão, das contribuições de campanha e do sistema bipartidário. Esses servidores planejam e administram o sistema escolar e universitário que, por sua vez, promove a socialização de cada geração favorável ao regime empresarial. O controle estatal do currículo requer o reinado dos administradores e contadores que, então, necessitam de uma pedagogia quantificável para controlar o que os professores e alunos fazem em cada sala de aula. Essa hierarquia considera que a abordagem da transferência de conhecimento é a mais adequada à manutenção da autoridade. (FREIRE; SHOR, 1986, p.51).

Temos consciência de que a realidade retratada por Freire e Shor (1986) não pode ser comparada mecanicamente ao momento atual, por possuir especificidades que não cabem aqui serem abordadas, mesmo assim as críticas escritas pelos autores mantem sua atualidade e podem muito ser adaptadas aos processos de avaliações externas em larga escala, conforme demonstra o trecho abaixo:

Pelo fato de que órgãos centrais impõem um programa padronizado e cada disciplina define a linguagem apropriada e as matérias de seu território acadêmico, a proposta oficial é que o ensino, em qualquer curso ou em qualquer classe, pode ser medido quantitativamente. Através de testes e medidas, as autoridades decidem se o dinheiro investido está ou não sendo bem gasto, cost-effective ou não, como dizem eles. Então, eles sabem se o tempo da escola está sendo bem usado ou não e se o 
educador profissional está merecendo o dinheiro que ganha. Uma certa quantidade de informação transferida a um certo número de alunos num dado período de tempo equivale a rigor, a dinheiro da escola bem gasto, e a salários de professores bem ganhos. Você vê como a "cultura dos negócios" está por trás do "rigor" tradicional? (FREIRE; SHOR, 1986, p.53, grifos nossos).

Não é difícil encontrarmos autores que mais recentemente, se aproximam das críticas e sugestões sobre os mesmos temas destacados acima. Paro (2012, p. 597), por exemplo, propõe que a avaliação seja realizada internamente, ou seja, "a institucionalização da avaliação interna do desempenho docente por parte dos próprios professores".

A esse respeito, pode-se pensar em duas medidas que se complementam: a autoavaliação e a avaliação recíproca. A primeira, como o próprio nome indica, deve ser feita pelo docente, levando em conta critérios gerais de desempenho que podem ser estabelecidos e negociados no interior do grupo de professores, a partir de sugestões feitas no âmbito do sistema (PARO, 2012, p. 597).

Para o autor, deve-se recusar o caráter que as avaliações vêem assumindo, ou seja, “A avaliação deve ser necessariamente qualitativa, fugindo às burocráticas pontuações e aos injustificáveis e odiosos rankings" (PARO, 2012, p. 597).

\section{CONSIDERAÇÕES FINAIS}

Ao observarmos o fenômeno de definição das políticas públicas percebemos um elemento marcante de desvinculação entre aqueles que pesquisam a educação e os que implementam as políticas. Denota-se uma nítida imposição dos princípios neoliberais, conforme apontou Tedesco (2012, p. 65-66), ao tratar desse tema, destacando que a voz dos pesquisadores é sempre ouvida

[...] a posteriori dos acontecimentos provocados pelas mudanças e costumam estar dirigidos a identificar suas limitações ou explicar seu fracasso. Os protagonistas das transformações, porém, costumam falar $a$ priori ou durante os processos para justificar, para convencer ou para dar publicidade ao que estão fazendo. Ao contrário dos pesquisadores são raras as ocasiões nas quais os atores das reformas tentam explicar as dificuldades que enfrentam ... Esse fenômeno tem provocado o empobrecimento mutuo. Os pesquisadores costumam ter um escasso conhecimento das características específicas da gestão das mudanças educacionais e os políticos da educação não dispões de um capital de conhecimentos sistematizados, que possam recorrer nem ao qual possam incrementar com suas experiências. 
Com base nos apontamentos aqui realizados, concluímos que as políticas de avaliação da educação básica se configuram de forma diferenciada do que foram no passado, se inserem num contexto em que se aplicam práticas de "quase-mercado" à educação pública. Assumem, assim, um caráter de uma mercadoria, portanto, sujeita à regulação do Estado, que tem nas avaliações externas em larga escala um dos instrumentos de controle do processo educacional, com especial ênfase na questão curricular.

Por fim, cabe ressaltar que esse processo não é novo e que as críticas as suas consequências são igualmente datadas. Recorremos ao pensamento freireano com a intencionalidade de obter contribuições, sobretudo, por entendermos que sua proposta corrobora o pensamento daqueles que querem uma educação criativa, cidadã e transformadora da realidade, em oposição ao modelo que vem sendo implantado, baseado na competição entre os sujeitos e entre as escolas, mediado pelo controle onipresente do Estado e materializado pelas avaliações.

\section{REFERENCIAS}

BEISIEGEL, C. R. A qualidade do ensino a escola pública. Brasília: Liber Livros, 2005.

BONAMINO, A.; SOUSA, S.Z. Três gerações de avaliação da educação básica no Brasil: interfaces com o currículo da/na escola. Educação e Pesquisa. 2012, vol.38, n.2. http://dx.doi.org/10.1590/S1517-97022012005000006

CHESNAIS, F. A Mundialização do Capital. São Paulo: Xamã, 1996.

FREIRE, P. Política e educação: ensaios. 5ạ. ed. São Paulo: Cortez, 2001. (Coleção Questões de Nossa Época; v.23).

FREIRE, P.; SHOR, I. Medo e Ousadia: o cotidiano do professor, 2a.ed. Rio de Janeiro: Paz e Terra, 1986.

MARTINS, A. M.; SOUSA, S. Z. A produção científica sobre avaliação educacional e gestão de sistemas e de escolas: o campo da questão entre 2000 e 2008. Ensaio: avaliação em políticas educacionais, vol. 20, no. 74, Rio de Janeiro, jan./mar. 2012.

PARO, V. H. Trabalho docente na escola fundamental: questões candentes. Cadernos de Pesquisa, v.42, no.146, p.586-611, maio/ago. 2012.

PERONI, V.; ADRIÃO, T. (orgs.) O público e o privado na educação: interfaces entre Estado e Sociedade. São Paulo, Xamã, 2005. 
SOUZA, S. Z. L. de; OLIVEIRA, R. P. de. Políticas de avaliação da educação e quase mercado no Brasil. Educação e Sociedade, 2003, vol.24, no. 84. http://dx.doi.org/10.1590/S0101$\underline{73302003000300007}$

TEDESCO, J. C. Qualidade da Educação e Políticas Educacionais. Brasília: Liber Livros, 2012.

WERLE, F. A. C. Políticas de avaliação em larga escala na educação básica: do controle de resultados à intervenção nos processos de operacionalização do ensino. Ensaio: avaliação em políticas educacionais, vol. 19 no.73, Rio de Janeiro, out./dez. 2011. 